\section{THIS}

EDITORIALS
E-SPECIES Zoologists should follow botanists into the digital age $\mathbf{p . 4 2 4}$
WORLD VIEW Meet the world'S only blogging stem-cell scientist $\mathbf{p . 4 2 5}$
MAN BITES DOG Ancient canines more than best friends $\mathbf{p . 4 2 7}$

\title{
The legacy of Doctor Moreau
}

\author{
Regulators must look past visceral disgust about human-animal hybrids. Strict but sensible rules \\ are needed for research on hybrid embryos and chimaeric animals that could produce therapies.
}

$\mathrm{T}$ The science-fiction author H. G. Wells coined the term humanized animals in his 1896 novel The Island of Doctor Moreau. The book invited readers to consider the ethical limits of curiosity-driven research and to ponder the moral value of the distinction between humans and animals. The book's evil protagonist creates, through a vaguely defined process of 'vivisection', a colony of half-human 'beast folk', unhappy in themselves and frightening to others.

Dr Moreau's humanized animals evoke visceral disgust. Thankfully, more than a century later, they remain science fiction. However, the ethical dilemmas presented by Wells do not.

Innumerable mice and other animals have been engineered in past decades to express a human gene and model specific aspects of human disease. They rarely inspire disgust, because they still resemble their own species. But further advances in genetic and stem-cell technologies mean that researchers could, in theory, create animals with quintessentially human characteristics or behaviours. The sight of an animal with shiny, furless 'human' skin, for example - exceptionally useful for research into skin disorders - could evoke disgust similar to that created by Moreau's beast folk, even though the animal itself might be perfectly comfortable. One of the biggest horrors - although technically unlikely - could be a self-aware monkey, a creature with human thought trapped in the body of an animal, unable to express itself.

Prompted by the possibilities, scientists around the world have begun to discuss the ethical consequences of taking to extremes the frontier technologies that allow mixing of species. These include the introduction of human stem cells into animals, where they could integrate into the animal's body; or the formation of hybrid or chimaeric embryos that mix the DNA of humans and animals.

The UK Academy of Medical Sciences in London has now produced a comprehensive report on the subject (see page 438 and page 448). The document is likely to lead to pioneering legislation specifically geared towards regulating research on animals containing human material. This is a timely and important step: timely because little truly controversial research in this area has yet been done, so both public debate and scientific research can take place in a peaceful environment; important because instinctive revulsion should not automatically block future research that will undoubtedly pave the way for therapies for currently incurable diseases.

The report clearly identifies techniques that cannot yet be used ethically, including extensive humanization of the monkey brain or the development of embryos that mix DNA from humans and non-human primates. It distinguishes them from procedures such as the creation of transgenic mice that bear human genes, which the academy says require no oversight beyond the strict controls that already apply.

The academy says that further oversight of experiments that occupy the middle ground - perhaps the human-skinned animal — should assess, on a case-by-case basis, whether the benefits to understanding or to medicine from a particular research project outweigh the potential suffering of the animal involved, its cage mates or its carers.

The UK government commissioned the report and is likely to adopt its conclusions. In doing so, it will reinforce Britain's reputation as an attractive research environment, strictly controlled but without unwarranted hindrances. The country has some of the world's most stringent laws on the welfare of research animals, but also some of the most rational regulations for research using human embryonic stem cells. It
allows the creation of hybrid embryos that are

\section{"Advances in genetic and} stem-cell technologies could, in theory, create animals with quintessentially human characteristics." predominantly human - forbidden in many countries - as long as they are destroyed before they develop beyond the two-cell stage. Now the country seems ready to regulate hybrid embryos that are mainly animal, as well as chimaeric animals.

The United Kingdom knows that this will give it an advantage in reaping medical benefits - and that proactive legislation offers protection against future calls for outright bans, should public anxiety grow. Potential therapies using human stem cells to replace damaged organs or tissue must first be tested in animals. Chimaeric animals with human brain material might be useful. For example, they could help to establish how the normal human brain develops and functions, and what goes wrong in neurodevelopmental disorders such as schizophrenia.

The ethical questions raised by H. G. Wells are as valid today as they ever were. But as facts and fiction converge, the answers have become more complex.

\section{Heart of the matter}

\section{The Heartland Institute's climate conference reveals the motives of global-warming sceptics.}

I t would be easy for scientists to ignore the Heartland Institute's climate conferences. They are curious affairs designed to gather and share contrarian views, in which science is secondary to wild accusations and political propaganda. They are easy to lampoon delegates at the latest meeting of the Chicago-based institute in Washington DC earlier this month could pick up primers on the libertarian writings of Russian-American novelist Ayn Rand, who developed the philosophical theory of objectivism, and postcards depicting former US vice-president $\mathrm{Al}$ Gore as a fire-breathing demon. And they are predictable, with environmentalists often portrayed as the latest incarnation of a persistent communist plot. "Green on the outside, red on the inside," 